\title{
Weaning in italy between myths and reality
}

Volume 5 Issue 2 - 2017

\author{
Gabriele Rumi \\ Catholic University of the Sacred Heart, Italy
}

Keywords: weaning, breastfeeding, LTP, PR-10, CBP

\section{Opinion}

I've just gone through the first six months of my first child's life. As a clinical immunologist and allergist, as well as a parent I have found myself in some of the issues that many of us often face in our professional practice on a daily basis. My wife was luckily able to breastfeed my son until the age of six months, following the more recent guidelines in this area. ${ }^{1}$ After that time, however, we dealt with the insertion of the first solid foods in the child's diet. We started with the apple, as it often happens in Italy. ${ }^{2}$ At this point, I started having the first serious concerns. How can it all start from a food so particular and mostly peeled in such a coarse manner? And why does the indicated procedure let the infant to be exposed immediately to a small amount of protein allergens such as the lipid transfer protein (Mal d3) and pathogenesis-related ones - PR-10 (Mal d 1)? In fact, is not possible to establish which is the real amount of those proteins in our food.

Elegant works such as the paper of Pastor-Vargas and colleagues have shown that some of the most allergenic proteins-including also the Pru p3-come into contact with the immune system of the infant well before six months. ${ }^{3}$ As well as other proteins that are introduced prematurely, these are at the same time very dangerous. For example, concerning the PR10, we have introduced carrots in the vegetable broth used during the first months of weaning. The carrot PR-10 are less labile to digestion and heat, and this kind of protein would seem to be, together with those contained in soy and celery, the most indicted for systemic reactions. Why do we not reflect more deeply on the most common scenarios in order to raise awareness in different population. We should think about the most common allergens for every population and speculate how to introduce them in the infants weaning. How come that alongside the traditional food there are not integrated amounts of protein subsidiaries, belonging to genres of families as the PR-10 or the calcium binding protein that could improve the outcome of tolerance for different allergens? ${ }^{4}$ Why the scientific community does not invest more in such a delicate and complex area of interest? Shall we investigate what are the proteins and not the food to be introduced before the child consumption? Which kind of protein is better to introduce in maternal consumption during pregnancy and breastfeeding period? As an allergist and as a father I hereby submit these questions to the attention of the scientific community.
Correspondence: Gabriele Rumi, Catholic University of the Sacred Heart, Rome, Italy,, Tel 390-635-038-95+390-635-032-35, Email rumigabriele@gmail.com

Received:January 01, 1970 | Published: March 06, 2017

\section{Acknowledgements}

None.

\section{Conflicts of interest}

Author declares there are no conflicts of interest.

\section{Funding}

None.

\section{References}

1. Kramer MS, Kakuma R . Optimal duration of exclusive breastfeeding. Cochrane Database Syst Rev . 2012;8:CD003517.

2. McKean M, Caughey AB, Leong RE, et al. The Timing of Infant Food Introduction in Families With a History of Atopy. Clin Pediatr (Phila). 2015;54(8):745-51.

3. Pastor-Vargas C, Maroto AS, Díaz-Perales A, et al. Sensitive detection of major food allergens in breast milk: first gateway for allergenic contact during breastfeeding. Allergy . 2015;70(8):1024-1027.

4. Gomez F, Aranda A, Campo P, et al. High Prevalence of Lipid Transfer Protein Sensitization in Apple Allergic Patients with Systemic Symptoms. PLoS One. 2014;9(9):e107304. 